\title{
CORRIGENDUM, VOLUME 81
}

Ronald E. Bruck, Jr., An iterative solution of a variational inequality for certain monotone operators in Hilbert space, pp. 890-892.

On p. 890, replace the original condition (3) by:

(3) the conditions $\left\{\left[z_{n}, w_{n}\right]\right\} \subset A \cap(C \times H),\left\{w_{n}\right\}$ bounded, $z_{n} \rightarrow z$ weakly, $\lim \left(w_{n}-f, z_{n}-u_{0}\right)=0$ imply $z \in E$.

On p. 891 , replace the original condition (4) by:

(4) the conditions $\left\{\left[z_{n}, w_{n}\right]\right\} \subset A, z_{n} \rightarrow z$ weakly, $w \in A y, \lim \left(w_{n}-w, z_{n}-y\right)$ $=0$ imply $w \in A z$.

On p. 891 , line 4 , replace "strictly" by "strongly".

\section{ERRATUM, VOLUME 82}

Moshe Marcus and Victor J. Mizel, Extension theorems for nonlinear disjointly additive functionals and operators on Lebesgue spaces, with applications, $\mathrm{pp}$. $115-117$.

\section{REFERENCES}

3. I. Kluvanek and G. Knowles, Vector measures and control systems, North-Holland, Amsterdam and New York, 1976. 